\title{
PERCEPÇÃO DOS PROFESSORES SOBRE A POLÍTICA EDUCACIONAL NA CIDADE DO RIO DE JANEIRO - 2009/2016
}

\author{
Jairo Campos dos Santos, ${ }_{2}^{1}$ \\ Luiza Alves de Oliveira
}

Resumo: 0 presente trabalho procura analisar uma nova política pública educacional implementada na cidade do Rio de Janeiro, no período de 2009 até 2016, caracterizada por uma gestão com foco no gerencialismo público. 0 objetivo principal foi identificar se, no período analisado, a política educacional deixou para a cidade um legado positivo, de acordo com a percepção dos profissionais (professores) que viveram essa política antes, durante e depois de sua implementação. Ficou evidente que esses professores não ficaram satisfeitos com a referida política. Com exceção de alguns aspectos tipicamente profissionais e um de âmbito nacional, ficou claro observar a insatisfação do grupo e, principalmente, a baixa aderência às ideias implementadas durante os oito anos em que a política esteve em prática.

Palavras-chave: Políticas públicas. Educação. Rio de Janeiro.

\footnotetext{
Doutorado em Educação, na linha de Pesquisa Políticas e Instituições Educacionais - PPGE - UFRJ. Analista de Planejamento e Orçamento da Secretaria Municipal de Fazenda da cidade do Rio de Janeiro - SMF - PCRJ. E-mail: jairo06@uol.com.br

${ }^{2}$ Doutorado em Educação pela Universidade Federal do Rio de Janeiro - UFRJ. Professora Adjunta da Universidade Federal Rural do Rio de Janeiro - UFRRJ
} 


\title{
TEACHER'S PERCEPTION ON EDUCATIONAL POLICY IN THE CITY OF RIO DE JANEIRO - 2009/2016
}

\begin{abstract}
The present work seeks to analyze a new public educational policy implemented in the city of Rio de Janeiro, from 2009 to 2016, characterized by management with a focus on public management. The main objective was to identify whether educational policy left the city a positive legacy, according to the perception of professionals (teachers) who lived this policy before, during and after its implementation. It became clear that these teachers were not satisfied with the policy. With the exception of some typically professional aspects and one at a national level, it was clear to note the group's dissatisfaction and, mainly, the low adherence to the ideas implemented during the eight years in which the policy was in practice.
\end{abstract}

Keywords: Public policies. Education. Rio de Janeiro.

\section{PERCEPCIÓN DE LOS PROFESORES SOBRE LA POLÍTICA EDUCACIONAL EN LA CIUDAD DEL RÍO DE JANEIRO - 2009/2016}

Resumen: El presente trabajo busca analizar una nueva política pública educativa implementada en la ciudad de Río de Janeiro, en el período de 2009 hasta 2016, caracterizada por una gestión con foco en el gerencialismo público. El objetivo principal fue identificar si, en el período analizado, la política educativa dejó a la ciudad un legado positivo, de acuerdo con la percepción de los profesionales (profesores) que vivieron esa política antes, durante y después de su implementación. Es evidente que estos profesores no quedaron satisfechos con dicha política. Con excepción de algunos aspectos típicamente profesionales y uno de ámbito nacional, quedó claro observar la insatisfacción del grupo $y$, principalmente, la baja adherencia a las ideas implementadas durante los ocho años en que la política estuvo en práctica

Palabras clave: Políticas públicas. Educación. Río de Janeiro. 


\section{Introdução}

Em 2009, um novo grupo político, eleito no ano anterior, assume a prefeitura da cidade do Rio de Janeiro. Esse novo grupo definiu para a cidade suas políticas públicas para todas as áreas de ação municipal e dentro de um novo planejamento estratégico, que englobava diretrizes e metas para tentar superar os desafios identificados para atuar em várias frentes que, em princípio, beneficiariam toda a cidade, ou seja, a possibilidade de um verdadeiro legado de crescimento.

Especificamente a área educacional, motivo deste estudo, e identificada pelo novo governo como um dos desafios, possuía, naquele ano, uma estrutura de 1.063 escolas (138 em horário integral), 235 creches públicas municipais e 159 creches conveniadas. Essas unidades escolares atendiam 705.659 alunos, com 36.523 professores e 13.317 funcionários de apoio administrativo. Assim, o novo grupo político trouxe para essa imensa rede de educação pública municipal um conjunto de determinações legais e regulamentares que mudaram e romperam com a política governamental exercida anteriormente.

A partir deste contexto, este trabalho visa contribuir com as pesquisas sobre políticas públicas educacionais, utilizando uma imagem mais prática, ou seja, com uma visão sobre uma realidade objetiva, apresentando as percepções dos profissionais de educação que, durante oito anos, estabeleceram relação direta com essa nova política, seja atuando como professores, diretamente, ou exercendo suas atividades como parte de equipes gestoras nas escolas (diretores, diretores adjuntos e/ou coordenadores pedagógicos).

Não houve para este estudo a intenção de delinearmos os pormenores de cada ação de formulação da política educacional analisada e, também, sobre os aspectos de sua implementação, pois seria demasiado extenso. Na verdade, buscamos registrar os pontos cruciais e estruturais dessa política através dos olhos dos profissionais da própria rede de educação em estudo.

Esses pontos estão ligados à execução das metas estratégicas, aos aspectos de gestão e aos aspectos pedagógicos, tudo da política em estudo.

Dessa maneira, o objetivo principal para esta pesquisa está em identificar se, no período analisado, a política educacional deixou para a cidade um legado 
positivo, de acordo com a percepção dos profissionais que viveram essa política antes, durante e depois de sua implementação.

Para tanto, a construção deste trabalho buscará, inicialmente, discorrer de maneira resumida sobre processos de análises de políticas públicas e, também, sobre os fundamentos e aspectos gerais da política educacional aqui analisada. Em seguida, a caracterização e operacionalização da pesquisa empírica, sua descrição e análise dos dados coletados e, por fim, algumas considerações.

\section{Caminhos para Análise de Políticas Públicas Educacionais}

Sabemos que pensar sobre políticas de governo na área educacional e, principalmente, sobre a gestão educacional, numa visão que busque a qualidade, gera um desafio que envolve diversos interesses sociais (ou de grupos) e, da mesma maneira, concordamos com Moraes (2009), quando afirma que historicamente, no Brasil, o modo de se fazer política pública em educação, via de regra, é "intramuros", envolvendo em sua elaboração apenas a cúpula do Ministério da Educação e das Secretarias de Educação, ou seja, o Ministro/Secretário e suas respectivas assessorias.

Assim, ao buscarmos estudos e pesquisas sobre políticas públicas, identificamos que as macroanálises são predominantes e se distanciam das microanálises, que são aquelas que incluem a percepção dos que estão diretamente envolvidos no processo e onde ele realmente ocorre, ou seja, uma análise no interior das instituições ou, como se diz informalmente: no campo.

Esse fato, a ser pensado também como fruto de um estudo, demonstra um diagnóstico aferido na implantação de políticas públicas educacionais no Brasil, pois como menciona Capela (2017), essa noção culminou com mudanças na gestão das políticas educacionais, onde ajustes jurídicos possibilitaram a criação de mecanismos políticos, administrativos e pedagógicos capazes de concretizar a melhoria na qualidade educacional por meio do controle de resultados, via política de avaliação e responsabilização, afetando a dinâmica das unidades escolares no trato de suas práticas pedagógicas.

A teoria caracteriza alguns mecanismos para análise de políticas públicas. $\mathrm{Na}$ verdade, são modelos que evidenciam a política na sua elaboração, na sua 
implementação e nos seus resultados, conforme podemos identificar nos estudos de Cavalcanti (2013), Moraes (2009), Perez (2010), Trevisan e Bellen (2008) entre outros, que para este estudo foram referências, não só por tratarem de políticas educacionais, mas de políticas públicas em geral.

Contudo, a perspectiva que nos orientou para este trabalho foi o estudo encontrado no trabalho de Passone (2013), que trata de contribuições sobre o estudo de implementação de políticas educacionais. Esse estudo demonstra que três aspectos afetam a análise da implementação de políticas públicas educacionais e o autor os define da seguinte maneira:

Desse modo, na atualidade, as análises de implementação educacional têm investigado de modo particular como tais dimensões afetam, moldam e determinam os resultados das políticas e programas educacionais. A dimensão da política envolve as metas, os alvos e as estratégias previstas para sua implementação. Já a dimensão dos atores inclui tanto os destinatários formais da policy, quanto os grupos informais, grupos e subgrupos profissionais, os policy-markers, as comunidades e associações da sociedade civil. E, por último, a dimensão de contexto envolve tanto o espaço físico habitado pelas organizações, sua jurisdição, seu contexto histórico e institucional, quanto às relações sistêmicas que se desdobram no processo de implementação. (PASSONE, 2013, p. 606).

Assim, de acordo com o posicionamento mencionado acima e, também, dentro do objetivo deste trabalho, escolhemos a dimensão atores, especificamente, com relação aos grupos e subgrupos profissionais que atuaram na política educacional aqui investigada, para serem os avaliadores da mesma, através de suas percepções e, dessa forma, contribuírem para o estudo empírico aqui desenvolvido.

Ainda para Passone (2013, p. 608):

[...] os estudos contemporâneos começaram a investigar as diferenças existentes entre os diferentes subgrupos profissionais, em vez de se limitarem, como os estudos tradicionais, a buscar conhecer em que medida os grupos profissionais (professor, supervisor, secretário), enquanto grupos institucionalizados, assumiam ou não os interesses, crenças, valores, ideias, o conhecimento e outras orientações formadas a partir de sua própria participação na implementação.

Corroborando com a afirmativa acima, procuramos registrar, analisar e compreender a percepção dos profissionais participantes deste estudo com relação à política educacional pública na cidade do Rio de Janeiro, no período de 2009 até 
2016, pois esse posicionamento é dinâmico, intrínseco e, em muitos casos, preponderante nas ações para o alcance dos objetivos fins da educação.

\section{A Política Pública Educacional Objeto de Análise}

O novo governo eleito em 2008 e empossado no ano seguinte usou como uma das plataformas políticas exatamente a questão educacional, principalmente, com o discurso crítico recorrente sobre a “aprovação automática”, que nunca foi bem compreendida pelos cidadãos e, também, pelos profissionais de educação que trabalharam com o sistema de ciclos, deixando margem para uma evidente progressão sem aprendizagem.

Essa compreensão equivocada sobre o sistema de ciclos na prática e na teoria ou, até mesmo, uma compreensão parcial pode ser encontrada em diversos trabalhos como o de Arroyo (1999), que reflete sobre o caráter formador do repensar das concepções e práticas de formação que acontecem na implantação dos ciclos, de Barretto e Souza (2004), que revela diversos estudos sobre ciclos e progressão escolar no Brasil, de Fetzner (2009), que indica elementos de transição cultural, política e pedagógica nos cotidianos escolares, a partir do uso do sistema de ciclos e, também, em diversos outros, que terminam por demonstrar que a implantação do sistema de ciclos trouxe para diversas redes de ensino muita instabilidade, pois necessitaria de uma capacitação e/ou formação específica dos profissionais para uma correta compreensão e aplicação do processo fato que, na maioria dos casos, não ocorreu de forma adequada, inclusive no sistema municipal público da cidade do Rio de Janeiro.

Observamos que esse sistema estava mergulhado nessa "confusão" no final de 2008 e, para mudar aquela realidade, as propostas estratégicas iniciais da nova política educacional se fixaram nas seguintes metas para o período de 2009-2012, retiradas do documento denominado Plano Estratégico da prefeitura do Rio de Janeiro 2009 - 2012. (RIO DE JANEIRO, 2008), como:

- Obter uma nota média (entre as escolas públicas municipais) igual ou superior a 5,1 para os anos iniciais e a 4,3 para os anos finais no IDEB ${ }^{3}$ em 2011.

\footnotetext{
3 Índice de Desenvolvimento da Educação Básica
} 
- Criar 30.000 novas vagas em creches públicas ou conveniadas até 2012.

- Criar 10.000 novas vagas em pré-escolas públicas até 2012.

- Garantir que pelo menos $95 \%$ das crianças com sete anos de idade, ao final do ano de 2012, estejam alfabetizadas.

- Reduzir para menos de $5 \%$ a taxa de analfabetismo funcional entre os alunos do $4^{\circ}$ ao $6^{\circ}$ ano em 2012.

Essas metas, conforme observamos, possuem uma restrição temporal para 0 fim do primeiro quadriênio do governo, contudo o mesmo grupo político foi reeleito para o período seguinte, 2013-2016 e, em consequência, novas metas foram inseridas, de acordo com o documento denominado Plano Estratégico da prefeitura do Rio de Janeiro 2013 - 2016 (RIO DE JANEIRO, 2012), a saber:

- Obter uma nota média, entre as escolas públicas municipais, igual ou superior a 6,0 para os Anos Iniciais e igual ou superior a 5,0 para os anos finais do IDEB em 2015.

- Garantir que, pelo menos, $95 \%$ das crianças com sete anos de idade ao final do ano de 2016 estejam alfabetizadas.

- Reduzir para menos de $5 \%$ a taxa de analfabetismo funcional entre os alunos do $4^{\circ}$ ao $6^{\circ}$ ano em 2016.

- Ter pelo menos $35 \%$ dos alunos da rede municipal em tempo integral até 2016.

- Garantir que $96 \%$ dos alunos da rede municipal se formem no $2^{\circ}$ segmento até os 16 anos.

- Criar 60 mil vagas para Educação Infantil entre 2009 e 2016.

Nesse estudo, não observamos nenhum motivo específico para a definição das metas acima descritas, com exceção do problema já mencionado sobre o sistema de ciclos. Entretanto, ficou muito claro que o modelo de gestão delineado através de metas, objetivos, remuneração extra para conquistas de resultados, responsabilização e outros, caracteriza que o gerencialismo (gestão gerencial) esteve presente, mesmo que sem uma definição clara e explícita de sua utilização, conforme observamos em Santos. (2014).

Ao registrarmos neste estudo as metas mencionadas anteriormente e, como já dito antes, sem entrarmos nos pormenores para sua implementação, buscamos 
fazer um levantamento sobre o percentual de execução (realização efetiva) dessas metas e/ou a informação sobre sua realização ou não, no âmbito de cada plano estratégico, seguindo os dados disponíveis nos órgãos oficiais de acompanhamento, controle e informação.

Esses dados são importantes, pois permitem substancializar 0 posicionamento dos professores que será apresentado na descrição e análise da pesquisa empírica.

Dessa maneira, inicialmente, eis o que foi identificado para o quadriênio de 2009-2012.

Tabela 1 - Informação sobre a execução das metas do quadriênio 2009-2012

\begin{tabular}{|c|c|}
\hline Meta estratégica 2009-2012 & $\begin{array}{l}\text { Percentual de execução/informação sobre } \\
\text { a execução }\end{array}$ \\
\hline $\begin{array}{l}\text { Obter uma nota média (entre as escolas } \\
\text { públicas municipais) igual ou superior a 5,1 } \\
\text { para os anos iniciais e a } 4,3 \text { para os anos } \\
\text { finais no IDEB em } 2011 .\end{array}$ & $100 \%$ \\
\hline $\begin{array}{l}\text { Criar } 30.000 \text { novas vagas em creches } \\
\text { públicas ou conveniadas até } 2012 \text {. }\end{array}$ & $50,58 \%$ \\
\hline $\begin{array}{l}\text { Criar } 10.000 \text { novas vagas em pré-escolas } \\
\text { públicas até } 2012 \text {. }\end{array}$ & $\begin{array}{l}\text { * Meta extinta em razão da mudança na } \\
\text { idade de entrada no Ensino Fundamental, } \\
\text { pois a demanda originalmente prevista se } \\
\text { reduziu significativamente. }\end{array}$ \\
\hline $\begin{array}{l}\text { Garantir que pelo menos } 95 \% \text { das crianças } \\
\text { com sete anos de idade, ao final do ano de } \\
2012 \text {, estejam alfabetizadas. }\end{array}$ & $90,63 \%$ \\
\hline $\begin{array}{l}\text { Reduzir para menos de } 5 \% \text { a taxa de } \\
\text { analfabetismo funcional entre os alunos do } \\
4^{\circ} \text { ao } 6^{\circ} \text { ano em } 2012 \text {. }\end{array}$ & Meta não atingida \\
\hline
\end{tabular}

Fonte: Inep (2017) e Secretaria Municipal da Casa Civil do Rio de Janeiro (2013)

Já para o quadriênio de 2013-2016, a política introduzida avançou em busca de novas metas, além de tentar estabelecer o alcance de algumas que não foram atingidas no período anterior, contudo, para a apuração dos resultados de cada uma das metas, este estudo encontrou muitos limites.

0 principal limite decorre pelo fato de que, com a mudança de governo nas eleições municipais de 2016, na qual o partido da situação não conseguiu eleger seu candidato, o grupo político que assumiu o governo em 2017 não possuía e não possui 
nenhum interesse em apurar se o governo anterior cumpriu ou não suas metas. Com isso, mesmo tentando vários recursos e junto a diversos órgãos municipais, além da própria Secretaria Municipal de Educação da Cidade do Rio de Janeiro (2018), somente foi possível apurar a execução de três metas, conforme abaixo.

Tabela 2 - Informação sobre a execução das metas do quadriênio 2013-2016

\begin{tabular}{l|c}
\multicolumn{1}{c|}{ Meta estratégica 2013-2016 } & $\begin{array}{c}\text { Percentual de execução/informação sobre } \\
\text { a execução }\end{array}$ \\
\hline $\begin{array}{l}\text { Obter uma nota média, entre as escolas } \\
\text { públicas municipais, igual ou superior a 6,0 } \\
\text { para os Anos Iniciais e igual ou superior a } \\
5,0 \text { para os Anos Finais do IDEB em 2015. }\end{array}$ & Meta não atingida \\
\hline $\begin{array}{l}\text { Garantir que, pelo menos, 95\% das crianças } \\
\text { com sete anos de idade ao final do ano de }\end{array}$ & Execução da meta sem informação \\
$\begin{array}{l}2016 \text { estejam alfabetizadas. } \\
\text { Reduzir para menos de } 5 \% \text { a taxa de } \\
\text { analfabetismo funcional entre os alunos do } \\
4^{\circ} \text { ao } 6^{\circ} \text { ano em } 2016 .\end{array}$ & Execução da meta sem informação \\
\hline $\begin{array}{l}\text { Ter pelo menos } 35 \% \text { dos alunos da rede } \\
\text { municipal em tempo integral até } 2016 .\end{array}$ & $96,28 \%$ \\
\hline $\begin{array}{l}\text { Garantir que } 96 \% \text { dos alunos da rede } \\
\text { municipal se formem no } 2^{\circ} \text { segmento até os } \\
16 \text { anos. }\end{array}$ & Execução da meta sem informação \\
\hline $\begin{array}{l}\text { Criar } 60 \text { mil vagas para Educação Infantil } \\
\text { entre } 2009 \text { e } 2016\end{array}$ & $50,97 \%$ \\
\hline
\end{tabular}

Fonte: Inep (2017) e Secretaria Municipal da Casa Civil do Rio de Janeiro (2013).

Diante de obstáculos para encontrar os dados de realização ou não das metas estratégicas para o período de 2013-2016, fica evidenciada, preliminarmente, a maneira como as políticas públicas são implementadas e executadas, ou seja, sem nenhuma preocupação em passar para a sociedade quais os resultados alcançados com a aplicação dos recursos públicos existentes e, talvez, o principal, a falta de continuidade das políticas, pois cada governo cria e implanta a sua política, do seu modo, com o seu interesse. Um verdadeiro descompromisso social.

\section{Características e Operacionalização da Pesquisa Empírica}

Para a observação e análise das percepções dos profissionais de educação, que estiveram diretamente envolvidos no processo de implementação e execução da política educacional aqui em estudo, utilizamos alguns critérios que buscaram 
trazer uma observação robusta e confiável, pois como afirmam Trevisan e Ballen (2008, p. 8):

As avaliações podem ser um "problema” para os governantes, executores e gerentes de projetos porque os resultados podem causar constrangimentos públicos. As informações e resultados das avaliações podem ser usados pelo público e pela imprensa para criticar os governos, da mesma forma que, em caso de "boas notícias", os governos podem usá-las para legitimar as próprias políticas, como ganho político etc.

Com isso, inicialmente, para definir um grupo de participantes da pesquisa, que seja considerado significativo e confiável, utilizamos uma amostra da população total, que contivesse, segundo análise de probabilidades e cálculos matemáticos e estatísticos, um erro amostral em torno de 5\% (para mais ou para menos) e com um nível de confiança em torno de $95 \%$.

Dentro da população total de 41.216 professores, segundo informações de agosto de 2017 da própria SME, o instrumento de pesquisa foi respondido por 305 professores, que ocupavam e/ou ainda ocupam diversas funções nas escolas. Tal número está diversificado em várias unidades escolares da rede municipal de educação da cidade do Rio de Janeiro e, como todos são professores, um grande grau de homogeneidade desse aspecto está presente, conforme poderemos observar a seguir.

Outro critério, não menos importante, foi o conjunto que engloba a forma de criação e aplicação do instrumento de pesquisa.

Encontramos em Libâneo (2013), que o diretor ou gestor da escola é o responsável pelo funcionamento administrativo e pedagógico, desempenhando, principalmente, a gestão geral da instituição escolar.

Da mesma forma, tal situação é encontrada na afirmação de Lück (2009, p. 22):

Os gestores escolares, constituídos em uma equipe de gestão, são os profissionais responsáveis pela organização e orientação administrativa e pedagógica da escola, da qual resulta a formação da cultura e ambiente escolar, que devem ser mobilizadores e estimuladores do desenvolvimento, da construção do conhecimento e da aprendizagem orientada para a cidadania competente.

Já, de acordo com Paro, identificamos o seguinte:

[...] o problema central é que a escola tem-se estruturado a partir de um equívoco em seu objetivo e na forma de buscá-lo porque adota 
uma visão estreita de educação. Essa concepção impede que se perceba a especificidade do trabalho escolar e a necessidade de uma administração que corresponda a essa especificidade. Ao se ignorar a especificidade do trabalho pedagógico, toma-se 0 trabalho escolar como outro qualquer, adotando medidas análogas às que têm sido tomadas em outras unidades produtivas. (PARO, 2010, p. 774).

De acordo com o asseverado, buscamos para a criação dos itens que compõem 0 instrumento de pesquisa, desenvolver afirmações sobre aspectos que englobassem dois eixos básicos para a percepção de uma política pública educacional, por nós definidos, de acordo com o que identificamos sobre como avaliar uma política pública em educação, seguindo o conteúdo teórico de nosso principal referencial e, também, dos pesquisadores que analisam os processos de gestão escolar em todas suas variáveis.

Para tanto, identificamos estes eixos como: atividade pedagógica (fim) e atividade de gestão (meio). De fato, esses eixos são imbricados, pois agem de maneira simultânea no interior do ambiente escolar e, dessa maneira, tornam-se essenciais para a formulação de qualquer política educacional.

Dessa forma, e confirmando a possibilidade de um caminho correto para a definição, composição e elaboração de conteúdos para os eixos propostos, encontramos em Krawczyk (1999, p. 14) que:

[...] ao pensar a gestão escolar, estamos necessariamente erguendo uma ponte entre a gestão política, a administrativa e a pedagógica. $\mathrm{Ou}$ seja, a gestão escolar não começa nem termina nos estabelecimentos escolares, tanto que não se trata de unidades auto-suficientes para promover uma educação de qualidade com equiidade.

Já em Vieira (2007, p. 67) temos que:

0 dilema dos que pensam a gestão é de que se bastam com a teoria. Não sujam as mãos com a prática, ou com a 'rica totalidade de determinações e de relações numerosas'. 0 dilema dos que fazem a gestão reside no extremo oposto. Se os primeiros se contentam com a teoria, os segundos limitam-se à prática, problema igualmente ardiloso, com implicações distintas.

Após o encontro com as posições acima e, tomando por base a experiência prática, além de inúmeros relatórios e questionários que fazem parte do cotidiano escolar e que buscam, de uma forma ou de outra, captar, embora nunca 
profundamente, as questões ligadas a aspectos importantes de políticas públicas implementadas, sejam específicas aos processos de avaliação ou, até mesmo, com relação à participação democrática na escola, sintetizamos, após testes de uniformidade de conteúdo, linguagem e aceitação, 16 (dezesseis) afirmações, sendo 8 (oito) intimamente ligadas aos aspectos pedagógicos e 8 (oito) ligadas aos aspectos de gestão e que foram distribuídas da seguinte maneira:

Tabela 3 - Afirmações do instrumento de pesquisa

\begin{tabular}{|c|c|c|}
\hline 1 & $\begin{array}{c}\text { Aspectos } \\
\text { pedagógicos }\end{array}$ & $\begin{array}{l}\text { No período de } 2009 \text { até } 2016 \text {, em sua opinião, houve melhorias no } \\
\text { sistema educacional público da cidade do Rio de Janeiro. }\end{array}$ \\
\hline 2 & $\begin{array}{c}\text { Aspectos } \\
\text { pedagógicos }\end{array}$ & $\begin{array}{l}\text { No período de } 2009 \text { até 2016, SUA ESCOLA teve progresso com } \\
\text { relação ao desempenho dos alunos. }\end{array}$ \\
\hline 3 & $\begin{array}{c}\text { Aspectos } \\
\text { pedagógicos }\end{array}$ & $\begin{array}{l}\text { Durante o período de } 2009 \text { até 2016, novas práticas de ensino foram } \\
\text { desenvolvidas. }\end{array}$ \\
\hline 4 & $\begin{array}{c}\text { Aspectos } \\
\text { pedagógicos }\end{array}$ & $\begin{array}{l}\text { A sua unidade escolar cumpriu ou, ao menos, tentou cumprir o seu } \\
\text { Projeto Político Pedagógico em todo período de } 2009 \text { até } 2016 \text {. }\end{array}$ \\
\hline 5 & $\begin{array}{c}\text { Aspectos } \\
\text { pedagógicos }\end{array}$ & $\begin{array}{l}\text { Em sua unidade escolar existiram momentos de discussões sobre as } \\
\text { práticas pedagógicas introduzidas no período de } 2009 \text { até } 2016 \text {. }\end{array}$ \\
\hline 6 & $\begin{array}{c}\text { Aspectos } \\
\text { pedagógicos }\end{array}$ & $\begin{array}{l}\text { No período de } 2009 \text { até 2016, houve uma preocupação constante } \\
\text { com a Educação Especial. }\end{array}$ \\
\hline 7 & $\begin{array}{l}\text { Aspectos } \\
\text { pedagógicos }\end{array}$ & $\begin{array}{l}\text { A política educacional implementada no período de } 2009 \text { até } 2016 \\
\text { desenvolveu projetos para melhorar a aprendizagem de alunos com } \\
\text { dificuldade. }\end{array}$ \\
\hline 8 & $\begin{array}{c}\text { Aspectos } \\
\text { pedagógicos }\end{array}$ & $\begin{array}{l}\text { Projetos descontinuados não afetaram a política educacional } \\
\text { implementada no período de } 2009 \text { até } 2016 \text {. }\end{array}$ \\
\hline 9 & $\begin{array}{l}\text { Aspectos de } \\
\text { gestão }\end{array}$ & $\begin{array}{l}\text { Durante o período de } 2009 \text { até } 2016 \text {, toda política educacional foi } \\
\text { mantida sem alterações e tudo sempre foi bastante claro. }\end{array}$ \\
\hline 10 & $\begin{array}{l}\text { Aspectos de } \\
\text { gestão }\end{array}$ & $\begin{array}{l}\text { Durante o período de } 2009 \text { até 2016, as categorias profissionais } \\
\text { ligadas à educação tiveram valorização em todos os aspectos. }\end{array}$ \\
\hline 11 & $\begin{array}{l}\text { Aspectos de } \\
\text { gestão }\end{array}$ & $\begin{array}{l}\text { Durante o período de } 2009 \text { até 2016, a infraestrutura das escolas foi } \\
\text { aprimorada com obras e melhorias. }\end{array}$ \\
\hline 12 & $\begin{array}{l}\text { Aspectos de } \\
\text { gestão }\end{array}$ & $\begin{array}{l}\text { A política educacional pública no município do Rio de Janeiro, no } \\
\text { período de } 2009 \text { até } 2016 \text {, sempre incentivou a participação de toda } \\
\text { a comunidade escolar nos diversos momentos. }\end{array}$ \\
\hline 13 & $\begin{array}{l}\text { Aspectos de } \\
\text { gestão }\end{array}$ & $\begin{array}{l}\text { No período de } 2009 \text { até 2016, os gestores das unidades escolares } \\
\text { desenvolveram mecanismos que permitiram uma avaliação de suas } \\
\text { atividades pela comunidade escolar. }\end{array}$ \\
\hline 14 & $\begin{array}{l}\text { Aspectos de } \\
\text { gestão }\end{array}$ & $\begin{array}{l}\text { A política educacional implementada no período de } 2009 \text { até } 2016 \\
\text { permitiu que se aumentasse o volume dos recursos dentro da escola. }\end{array}$ \\
\hline 15 & $\begin{array}{l}\text { Aspectos de } \\
\text { gestão }\end{array}$ & $\begin{array}{l}\text { A alimentação dos alunos através da merenda escolar sempre foi } \\
\text { garantida durante a política educacional implementada no período } \\
\text { de } 2009 \text { até } 2016 \text {. }\end{array}$ \\
\hline 16 & $\begin{array}{l}\text { Aspectos de } \\
\text { gestão }\end{array}$ & $\begin{array}{l}\text { O programa de recompensas financeiras para os profissionais por } \\
\text { alcance de metas, durante a política educacional implementada no } \\
\text { período de } 2009 \text { até } 2016 \text {, foi positivo. }\end{array}$ \\
\hline
\end{tabular}

Fonte: Os Autores. 
Em avanço, para a aplicação do instrumento de pesquisa, desenvolvemos o conteúdo de informações sociodemográficas e as afirmações propriamente ditas, com o uso do aplicativo “Google Docs” e utilizamos a distribuição do mesmo através de plataformas de redes sociais, via link de acesso, com divulgação em vários grupos que professores da rede municipal de educação fazem parte, durante o período compreendido entre os meses do segundo semestre de 2017. Dessa maneira, a participação foi espontânea e voluntária.

0 posicionamento dos professores que participaram desta pesquisa foi manifestado para cada uma das 16 afirmações objetivas, através de gradações, que vão desde de "concordo", significando o maior grau de aceitação, passando pelo "indiferente", que demonstra nenhuma percepção, positiva ou negativa, e “discordo”, correspondendo ao maior grau de rejeição.

\section{Descrição e Análise dos Resultados da Pesquisa}

Inicialmente, sobre a análise dos dados sociodemográficos dos 305 profissionais participantes da pesquisa, identificamos o seguinte:

Gráfico 1 - Tempo de serviço na educação pública da cidade do Rio de Janeiro

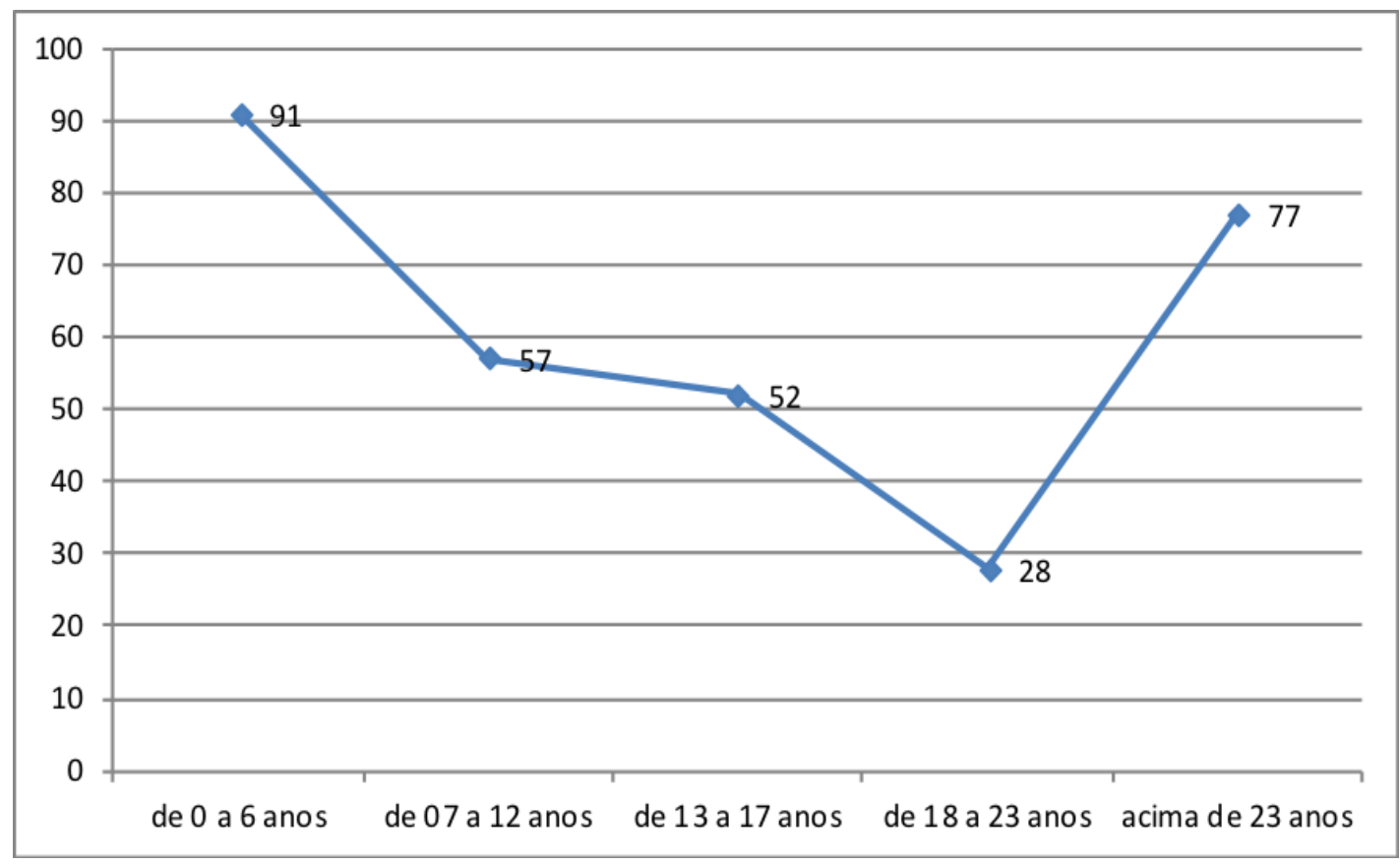

Fonte: Os autores (Análise dos dados da pesquisa) 
0 gráfico 1 demonstra maior frequência de respondentes em dois grupos de profissionais: docentes que possuem de 0 a 6 anos de efetivo exercício na rede municipal do Rio de Janeiro (91 profissionais) e docentes com mais de 23 anos de experiência no magistério da rede (77 profissionais). Uma leitura possível para estes dados assinalam uma participação significativa de grupos de professores que se encontram ora no início, ora no final da carreira profissional, o que nos dá o equilíbrio oportuno entre a visão dos que, a priori, ainda apresentam um comportamento crédulo e mobilizador nas ações inovadoras e a sensatez e criticidade muitas vezes próprias daqueles profissionais que já possuem experiência na docência, seja na regência de turma ou atuando em áreas administrativas.

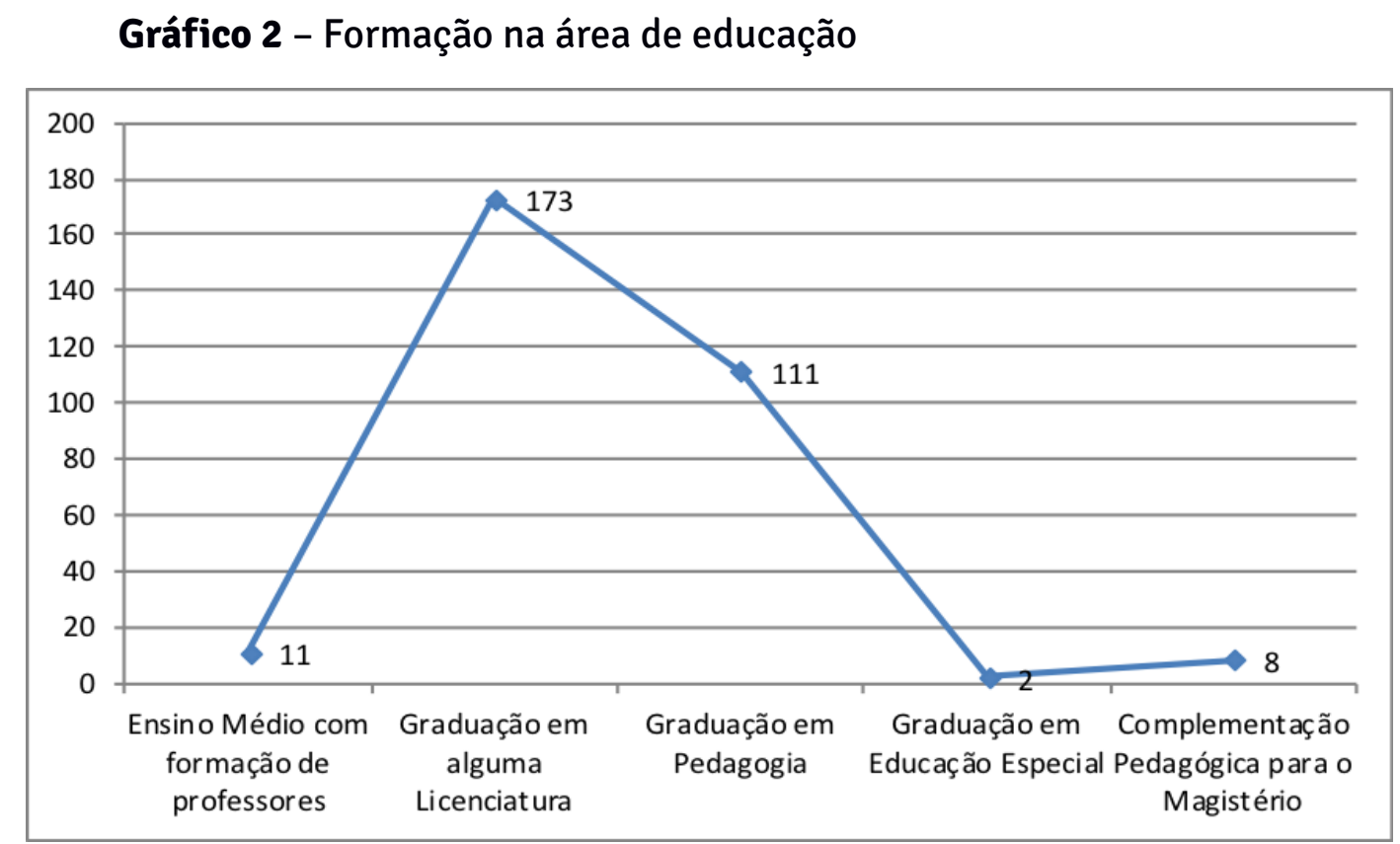

Fonte: Os autores (Análise dos dados da pesquisa)

Por sua vez, o gráfico 2 apresenta um mapeamento bastante satisfatório no que se refere à formação docente, pois a maioria dos profissionais da educação e participantes da pesquisa possuem formação pedagógica em nível superior: 173 concluíram alguma licenciatura e 111 são formados em Pedagogia. 
Gráfico 3 - Atividade exercida na escola

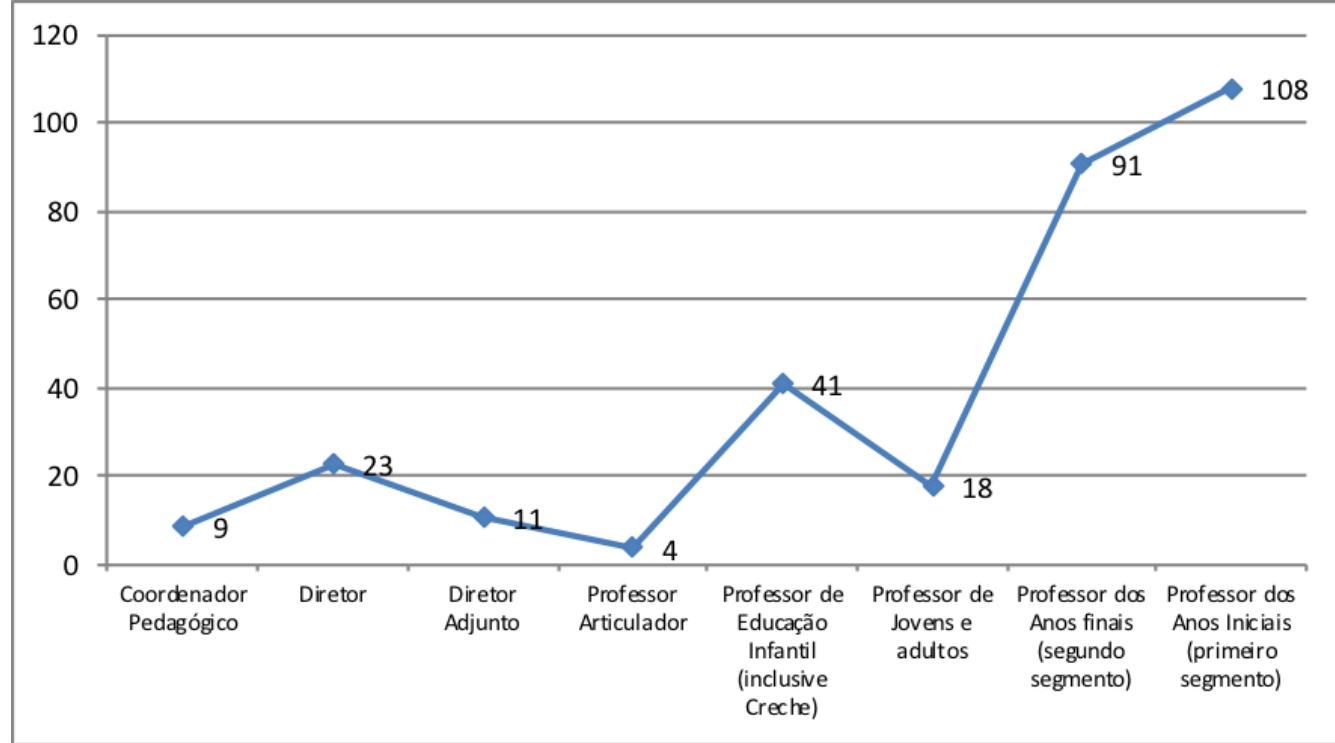

Fonte: Os autores (Análise dos dados da pesquisa)

Ainda sobre as informações que caracterizam os sujeitos pesquisados, destacamos, no gráfico 3, que a maior participação foi de professores que estão em sala de aula: 41 da Educação Infantil, 108 dos Anos Iniciais e 91 dos Anos Finais do Ensino Fundamental, o que implica em uma visão mais próxima da realidade da sala de aula. Os demais, atuando na direção e na coordenação/articulação pedagógica, embora em número mais reduzido e, à época da coleta de dados, não estivessem responsáveis por um grupamento/ano escolaridade, também contribuíram com importantes percepções sobre a política educacional pesquisada, exatamente por vivenciarem funções de gerenciamento e implementação de ações, tanto pedagógicas, como administrativas.

Em sequência, apresentamos a análise das percepções dos professores e, de acordo com a divisão proposta inicialmente pelo instrumento de pesquisa, a percepção vai ser aqui apresentada através da análise do posicionamento dos professores sobre dois aspectos: pedagógicos e gestão.

Para a análise, procuramos observar e sinalizar os maiores percentuais por afirmação sem, no entanto, fazer nenhuma correlação entre as respostas ou, até mesmo, entre as respostas e os grupos sociodemográficos.

As percepções, dessa maneira, terminam por serem objetivas e intimamente ligadas às afirmações e, por conseguinte, aos aspectos a que pertencem. 
Em princípio, pela análise dos dados sobre os aspectos pedagógicos, encontramos o seguinte:

\section{Gráfico 4 - Percepções sobre os aspectos pedagógicos}

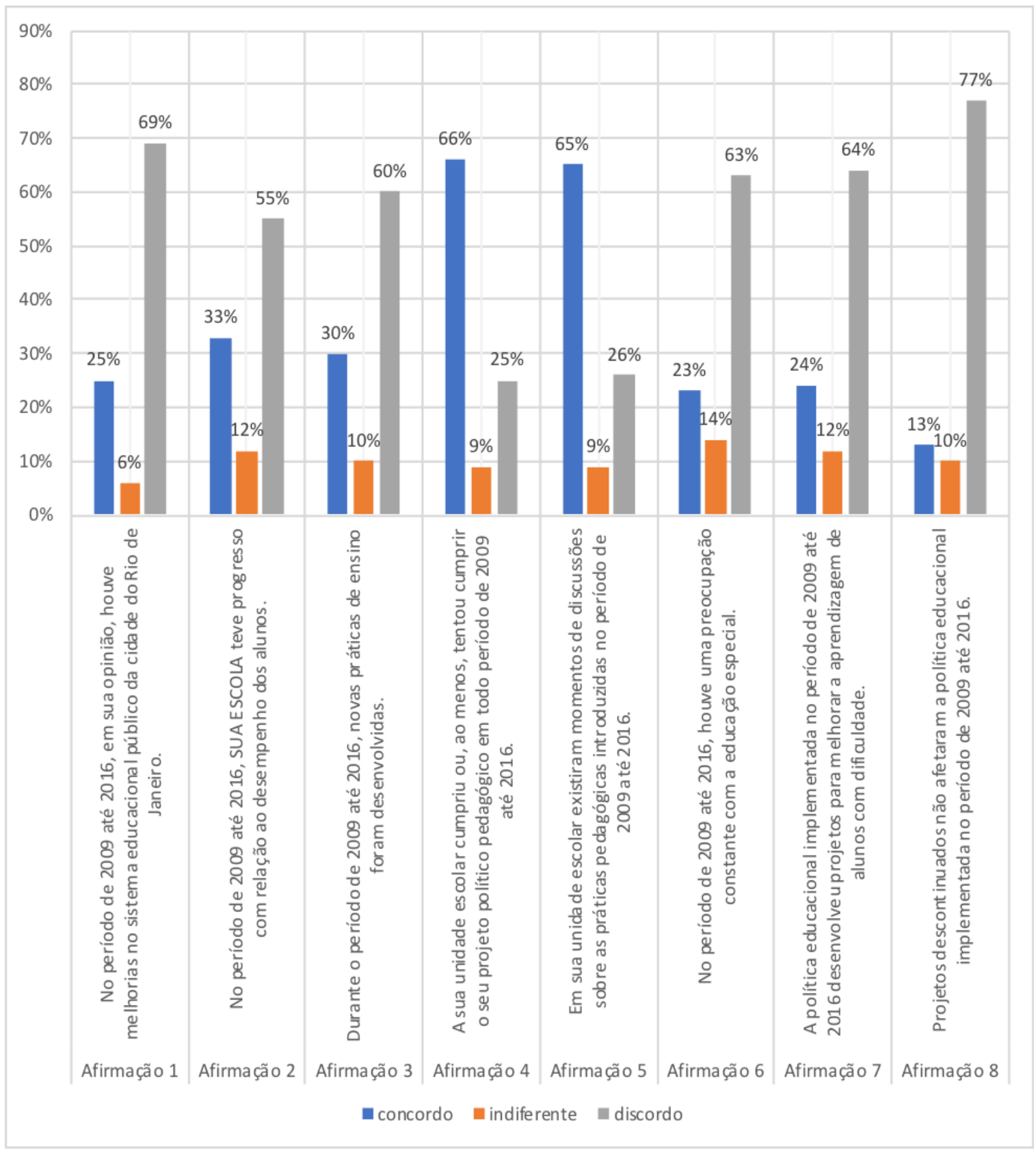

Fonte: Os autores (Análise dos dados da pesquisa)

Em análise, observamos que os professores, na sua maioria, dentro das afirmações que a eles foram expostas para avaliar, registraram que os aspectos pedagógicos não foram satisfatórios ou não corresponderam às expectativas. 
No entanto, em duas dessas afirmações (4 e 5), a maioria dos participantes da pesquisa concordou com as ações nelas propostas, fato que nos levou a observar que essas afirmações, apesar de serem estritamente ligadas a aspectos pedagógicos, possuem questões corporativas e de participação democrática no ambiente escolar e, tais fatos, trazem efetivamente ações de protagonismo nas atividades do magistério, sendo, dessa forma, afirmações que possuem aceitação, quase sempre, positiva por todo grupo de professores.

Já com relação aos aspectos de gestão, registramos o seguinte:

Gráfico 5 - Percepções sobre os aspectos de gestão

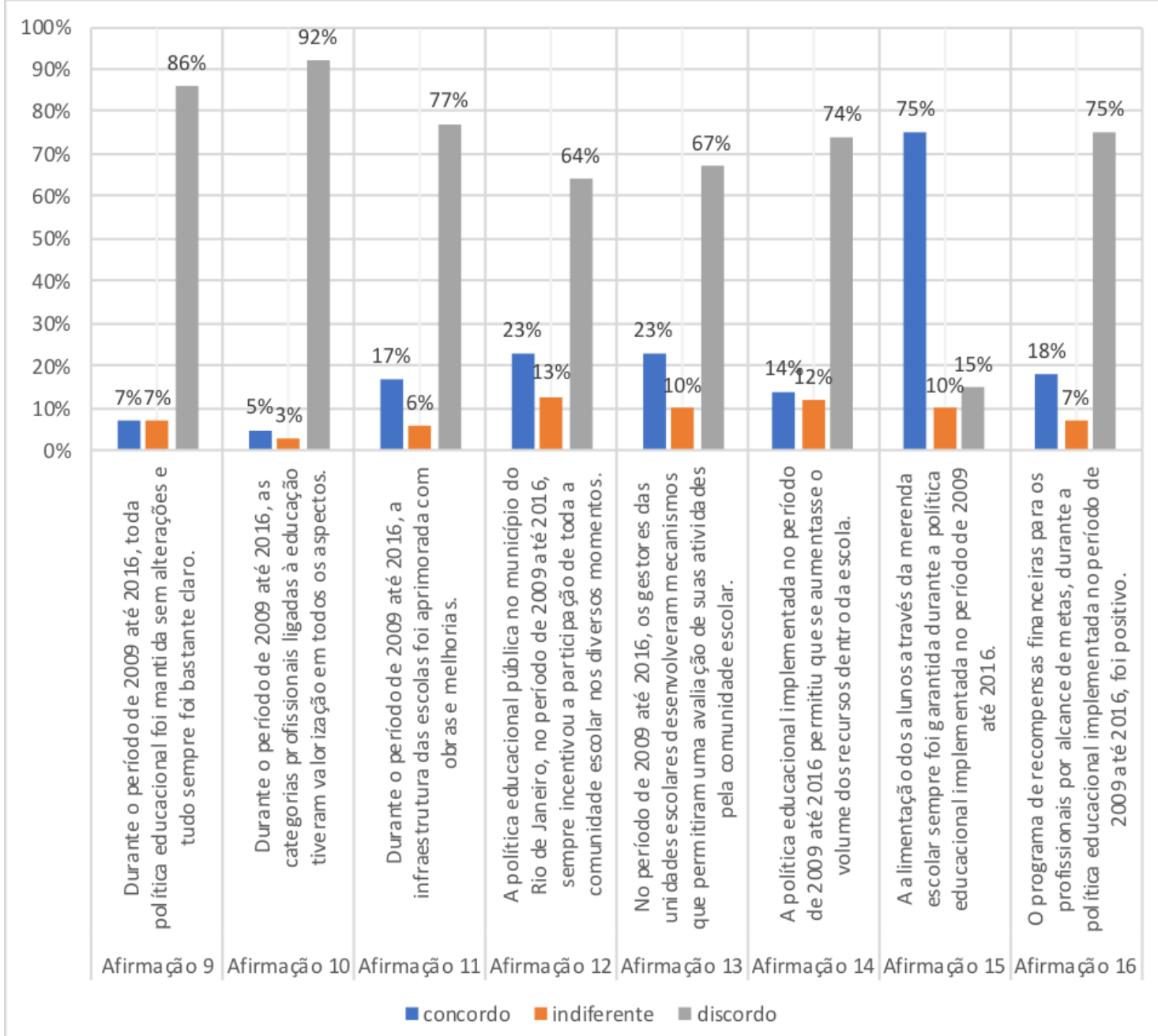

Fonte: Os autores (Análise dos dados da pesquisa)

De acordo com o analisado, podemos compreender sobre os dados acima que os professores perceberam as afirmações que compõem os aspectos de gestão com uma discordância quase unânime. Apenas a afirmação 15 possui uma aceitação positiva e tal fato é perfeitamente explicável, pois a alimentação dos alunos nas 
escolas públicas é um programa federal denominado Programa Nacional de Alimentação Escolar (PNAE) (BRASIL, 2018), ou seja, o poder público municipal tem apenas o trabalho de implementar a política de alimentação, com recursos, em sua maioria, oriundos do governo federal.

Tendo em vista a análise apresentada sobre os dois conjuntos de aspectos enfatizados neste estudo, podemos concluir que, segundo a visão dos professores, a política educacional, no período abordado, não conseguiu atingir um grau de aprovação satisfatório e tal fato termina por enfatizar o que já foi aqui demonstrado de acordo com os dados sobre a execução das metas planejadas pela política educacional.

\section{Conclusão}

Este estudo buscou, através de análise de dados, informações e percepções, compreender os resultados de uma política de governo para a educação pública numa das maiores cidades do país e termina por identificar, mesmo que de maneira não estanque, alguns aspectos que evidenciam uma baixa preocupação real com a melhoria da qualidade educacional.

De início, observamos que as metas planejadas para serem executadas, a priori, não apresentam condições de exequibilidade, pois não possuem um embasamento que as sustentem e, também, não trazem um estudo que as substanciem, sendo simplesmente partes de um Programa de propaganda política que servem pura e simplesmente para estampar apresentações de grupos que almejam se perpetuarem no poder, sem nenhum envolvimento sólido com a atividade educacional pública, haja vista a baixa execução positiva das mesmas.

$\mathrm{Na}$ verdade, a execução de metas da educação traduz diversas necessidades e não podem ser definidas de forma burocrática como geralmente ocorre e, também, envoltas de objetivos pirotécnicos, pois recursos públicos estão envolvidos e precisam ser corretamente utilizados.

Já ao analisarmos as percepções dos professores sobre a política objeto deste trabalho, na qual eles fizeram parte, concluímos que, na maioria dos aspectos traçados para captar uma visão mais fidedigna possível, ficou evidente que esses professores não ficaram satisfeitos com a referida política. Com exceção de alguns 
aspectos tipicamente profissionais e um de âmbito nacional, ficou claro observar a insatisfação do grupo e, principalmente, a baixa aderência às ideias implementadas durante os oito anos em que a política esteve em prática.

Verdadeiramente, oito anos com uma política educacional pública, que mostra baixos resultados nas metas por ela mesma traçada é preocupante, pois só demonstra que mais uma geração poderá se perder com um fraco aprendizado na parte mais preciosa da educação básica, onde conceitos e valores são enraizados.

Assim, esperamos que este trabalho possa contribuir para reflexões sérias junto a governos, planejadores e executores de políticas educacionais públicas, além dos pesquisadores da área, pois apesar de ser uma humilde contribuição possui reflexões importantes para as ações educacionais.

\section{Referências}

ARROYO, M. G. Ciclos de desenvolvimento humano e formação de educadores. Educação \& Sociedade, Campinas, v. 20, n. 68, p. 143-162, dez. 1999.

BARRETTO, E. S. S.; SOUSA, S. Z. Estudos sobre ciclos e progressão escolar no Brasil: uma revisão. Educação e Pesquisa, São Paulo, v. 30, n. 1, p. 31-50, jan./abr. 2004.

BRASIL. Ministério da Educação. Fundo Nacional de Desenvolvimento da Educação. Programa Nacional de Alimentação Escolar (PNAE). Brasília, DF: FNDE, 2018.

CAPELA, M. B. Qualidade do ensino sob a lógica do capital: o IDEB em foco. In: REUNIÃO NACIONAL DA ANPED, 38., 2017, São Luís. Anais [...]. São Luís: UFMA, 2017. Disponível em:

http://www.anped.org.br/news/38a-reuniao-nacional-da-anped-site-proprio. Acesso em: 22 jan. 2018.

CAVALCANTI, P. A. Análise de políticas públicas: o estudo do Estado em ação. Salvador: EDUNEB, 2013.

FETZNER, A. R. A implementação dos ciclos de formação em Porto Alegre: para além de uma discussão do espaço tempo escolar. Revista Brasileira de Educação, Rio de Janeiro, v. 14, n. 40, p. 51-65, jan./abr. 2009.

INEP - INSTITUTO NACIONAL DE ESTUDOS E PESQUISAS EDUCACIONAIS ANÍSIO TEIXEIRA. Consulta ao IDEB. Brasília, DF: INEP, 2017.

KRAWCZYK, N. A gestão escolar: um campo minado... Análise das propostas de 11 municípios brasileiros. Educação \& Sociedade, Campinas, v. 20, n. 67, p. 112-149, ago. 1999.

LIBANNEO, J.C. O sistema de organização e gestão da escola. In: LIBÃNEO, J. C. Organização e gestão da escola: teoria e prática. São Paulo: Heccus, 2013. p. 117-134. 
LÜCK, H. Dimensões de gestão escolar e suas competências. Curitiba: Editora Positivo, 2009.

MORAES, S. C. (Re) Discutindo a ação do estado na formulação e implementação das políticas educacionais. Educação, Porto Alegre, v. 32, n. 2, p. 159-164, maio/ago. 2009.

PARO, V. H. A educação, a política e a administração: reflexões sobre a prática do diretor de escola. Educação e Pesquisa, São Paulo, v. 36, n.3, p. 763-778, set./dez. 2010.

PASSONE, E. F. K. Contribuições atuais sobre o estudo de implementação de políticas educacionais. Cadernos de Pesquisa, São Paulo, v. 43, n. 149, p. 596-613, maio/ago. 2013.

PEREZ, J. R. R. Por que pesquisar implementação de políticas educacionais atualmente? Educação \& Sociedade, Campinas, v. 31, n. 113, p. 1179-1193, out./dez. 2010.

RIO DE JANEIRO. Prefeitura Municipal. Plano estratégico da prefeitura da cidade do Rio de Janeiro para o quadriênio 2009-2012. Rio de Janeiro: Prefeitura Municipal do Rio de Janeiro, 2008.

RIO DE JANEIRO. Prefeitura Municipal. Plano estratégico da prefeitura da cidade do Rio de Janeiro para o quadriênio 2013-2016. Rio de Janeiro: Prefeitura Municipal do Rio de Janeiro, 2012.

SANTOS, J. C. O gerencialismo no novo modelo de educação pública da cidade do Rio de Janeiro (2009-2012): origens, implantação, resultados e percepções. 2014. Tese (Doutorado em Educação) - Universidade Federal do Rio de Janeiro, Rio de Janeiro, 2014.

SECRETARIA MUNICIPAL DA CASA CIVIL (Rio de Janeiro). Informações Públicas. Rio de Janeiro: CVL, 2013. Disponível em: http://www.rio.rj.gov.br/cvl. Acesso em: 15 dez.2018.

SECRETARIA MUNICIPAL DE EDUCAÇÃO (Rio de Janeiro). Educação em Números. Rio de Janeiro: SME, 2018. Disponível em: http://www.rio.rj.gov.br/sme. Acesso em: 10 out. 2018.

TREVISAN, A. P.; BELLEN, H. M. Avaliação de políticas públicas: uma revisão teórica de um campo em construção. $R A P$, Rio de Janeiro, v. 42, n. 3, p.529-550, maio/jun. 2008.

VIEIRA, S. L. Política(s) e gestão da educação básica: revisitando conceitos simples. RBPAE, Rio Grande do SUl, v. 23, n. 1, p. 53-69, jan./abr. 2007

Recebido em: 27/09/2019

Aceito em: 19/12//2019 